IZA DP No. 9264

A Note on Possible Estimation Bias

When Studying Persons with Work Disability

in Active Labour Market Programs

Christer Gerdes

August 2015 


\title{
A Note on Possible Estimation Bias When Studying Persons with Work Disability in Active Labour Market Programs
}

\author{
Christer Gerdes \\ Swedish Public Employment Service, \\ SOFI, Stockholm University and IZA
}

Discussion Paper No. 9264

August 2015

\author{
IZA \\ P.O. Box 7240 \\ 53072 Bonn \\ Germany \\ Phone: +49-228-3894-0 \\ Fax: +49-228-3894-180 \\ E-mail: iza@iza.org
}

Any opinions expressed here are those of the author(s) and not those of IZA. Research published in this series may include views on policy, but the institute itself takes no institutional policy positions. The IZA research network is committed to the IZA Guiding Principles of Research Integrity.

The Institute for the Study of Labor (IZA) in Bonn is a local and virtual international research center and a place of communication between science, politics and business. IZA is an independent nonprofit organization supported by Deutsche Post Foundation. The center is associated with the University of Bonn and offers a stimulating research environment through its international network, workshops and conferences, data service, project support, research visits and doctoral program. IZA engages in (i) original and internationally competitive research in all fields of labor economics, (ii) development of policy concepts, and (iii) dissemination of research results and concepts to the interested public.

IZA Discussion Papers often represent preliminary work and are circulated to encourage discussion. Citation of such a paper should account for its provisional character. A revised version may be available directly from the author. 
IZA Discussion Paper No. 9264

August 2015

\section{ABSTRACT}

\section{A Note on Possible Estimation Bias When Studying Persons with Work Disability in Active Labour Market Programs*}

This study looks at the effects of participating in active labour market policy programs for persons with work disabilities. More in detail, it draws attention to the importance of taking into account the timing of when a work disability has been registered for persons attending ALMP programs. We argue that not controlling for time of events, i.e. the exact time a participant starts a program, as well as the time that person is being registered with a work disability, implies a risk of ending up with biased estimations with respect to the effectiveness of certain ALMP programs.

JEL Classification: C18, C52, D04, J18, H42

Keywords: $\quad$ work disability, ALMP programs, endogenous selection, post registration bias

Corresponding author:

Christer Gerdes

Swedish Public Employment Service

Department of Analysis

Research and Evaluation Unit

SE 11399 Stockholm

Sweden

E-mail: christer.gerdes@arbetsformedlingen.se

\footnotetext{
* I would like to thank Per Johansson and the staff at the Research and Evaluation Unit (especially Ann-Christin Jans and Gülay Özcan), for helpful comments on earlier drafts of the paper. Any opinions expressed here are those of the author and not those of the Swedish Public Employment Service.
} 


\section{Introduction}

This report looks at labour market outcomes following from participating in active labour market (ALMP) programs for persons with disabilities that imply reduced work capacity. The focus thereby is not on programs explicitly designed for persons with work disability, but programs that are open for the majority of persons registered as unemployed. More precisely, this study draws attention to the importance of taking into account the timing of when the work disability has been registered. Most evaluations of labour market programs build on data that typically is accessed long time after the period a researcher intends to analyse. From an evaluator's point of view it is rather common that one wants to assess the results of program participation in the medium to long term, which regularly implies a follow-up period of several years, or that one intends to follow historical patterns regarding effects of programs over the course of several years back in time.

Studies based on register data that measure the effects of ALMP programs hardly ever take into account the actual time when a disability code has been set. Regularly this follows from that most researchers rely on that statistical authorities are providing them with accurate data. However, as this report will show, researchers in the field of (ALMP) program evaluation should become aware of the possible endogeneity aspects that can arise due to subsequent updating of participants disability status. In praxis such process could look like as follows: the variable from registers that indicates if a person has some kind of disability is "empty" to begin with; at a later point in time he/she gets a disability registered, so that the variable indicating disability status will show some functional impairment. In practical terms this means that if one extracts data some years after the period one intends to study, it might look like that the person had his/her code registered for a much longer period of time 
than actually had been the case, sometimes even indicating that the code was set before the time that person took part in the program. This report shows that this "backdating" of coding of disability status could lead to misleading results and inaccurate conclusions about the effectiveness of labour market programs where persons with functional impairment participate.

The guidelines applied at the Swedish Public Employment Service (PES) regarding the recording of disability do not follow a rigorous and standardised order. According to Angelov and Eliason (2014b), who study the likelihood of getting a disability classification or not during the period 2003-2008, certain volume targets can determine who and how many persons that receive a disability registered. Certain measures, such as work aids or some forms of subsidized employment, require that the persons have received a disability classification before they can be assigned to such measures. To some extent, it can be said that the registration of a disability is related to the question of what measures should be taken to help that person. Angelov and Eliason (2014b) also points out that the fact that a disability is registered can have its downsides. This follows from that persons who get a code are at risk of being stigmatized, or that it can affect their self-perception in a negative way.

The remaining paper is structured as follows. Chapter 2 discusses implications following from the way registration of work disability is done and how this translates into a risk for biased estimations. For illustrational purposes, a simple model describing the mechanism underlying various forms of endogenity bias is introduced and discussed. Chapter 3 provides examples showing differences in outcomes of empirical estimations that take account of (i.e., eliminates cases of) post-registration of work disability compared to the situation when this is not been done, i.e. the way evaluations of ALMP programs usually are conducted. 
Chapter 4 provides a discussion of results and its implications for researchers, while chapter 5 concludes.

\section{Background and model}

Using Swedish data, Johansson and Skedinger $(2005,2009)$ have been able to show that there is a positive association between the duration of a person's unemployment period and her probability of getting a work disability code assigned. Their results are based on a comparison of records of work disability and participants' responses to questions regarding self-perceived health. They find that subsequent registration of a work disability over the course of a person's unemployment period typically is not matched by an according change of self-perceived health. Actually, being unemployed for some time might be taken as evidence that a functional disorder should be recorded as work disability, see Johansson and Skedinger $\left(2005\right.$, p. 36). ${ }^{1}$ That claim strongly underscores that there is an impending risk of endogenous selection of job seekers with work disabilities for ALMP program evaluations that aim to measure the impact of program participation.

\subsection{The model}

In order to facilitate understanding, one might think of a Becker-Mincer inspired analytical framework, where the outcome of interest is an individual's propensity of finding a job for

\footnotetext{
${ }^{1}$ That view is confirmed by Homqvist (2008), arguing that regularly job seekers who are classified as "disabled" do not consider themselves as having a work disability, but are encouraged to become registered with a disability code by case workers at the PES. A similar argument is made by Garsten and Jacobsson (2014), pointing to that being disabled can increase a person's chances of finding employment by means of ALMP measures that target persons with work disability "where a disability code is the path to special assistance and employment" p.845.
} 
persons being registered as unemployed. In the spirit of such a framework, as ingoing variables one might think of including age, gender, work experience, (length of) education, as well as other variables intended to capture productivity related characteristics. We consider employment training to be a human capital enhancing (dichotomous) factor that adds to other individual characteristics at a constant rate. ${ }^{2}$ The general model can then be formulated as follows:

Empl $=\beta_{1}$ age $+\beta_{2} a g e^{2}+\beta_{3}$ work experience $+\beta_{4}$ ecuation $+\beta_{5}$ empl training $+\boldsymbol{X} \boldsymbol{\beta}+\varepsilon$ Here the outcome is being employed or not in subsequent periods, vector $\boldsymbol{X}$ are other variables that can be observed in the data, while the residual term $\varepsilon$ includes remaining, possibly unobserved productivity related characteristics. As usual, all three human capital related aspects listed above, i.e. work experience, education, as well as employment training, are assumed to have a positive impact on the propensity of finding a job.

There are both persons with and without registered work disability among both participants and (would-be) control group members at the time they were registered as unemployed. Some form of functional impairment is one of several underlying individual fix characteristic of the persons under study, which for a number of persons are registered at an early stage, i.e. already at the time they become unemployed, while for others that status becomes registered at a later point in time; furthermore, for some persons their disability never show

\footnotetext{
${ }^{2}$ We are aware that this is a strong simplification of the standard way of modelling outflow to employment, disregarding aspects such as reservation wage, the wage offer distribution, intensity of job search activities, etc. Also, the marginal return of employment training can look rather different across groups, e.g. having larger impact for initially better educated persons. For a discussion and references on the importance of educational upgrade later in life on labour market outcomes, see Vono de Vilhena et al. (2012).
} 
up in the registers as they manage to leave unemployment for a job before such registration would be accomplished.

Being in the treatment or control group, i.e. what Lechner (2008) calls the "state of the world", will be denoted $S \in\{0,1\}$. To clarify subsequent discussion, let's think of a scenario where group assignment to treatment and control group has been perfectly random. The important aspect for the following discussion is that program assignment was not conditioned on persons having a diagnosed work disability or not.

There are three time periods to keep track of, i.e. period $t, t+1$ and $t+2$ : First, the program starts and ends in period $t$. The researcher is conducting her analysis of the program at period $t+2$ based on available information concerning period $t$ (e.g., participating in the program or not) as well as period $t+1$ (e.g., being employed or not). Furthermore, assume that the researcher only can observe the "disability" status for a person as it appears in the data in period $t+1$, i.e. the researcher does not know if (or is indifferent to the fact that) the disability was recorded in either period $t$ or $t+1$. Individuals are matched according to information on individual characteristics, i.e. with respect to disability status as well as other variables that are available in the registers in period $t+2 .{ }^{3}$ As outlined before, here the researcher aims to study persons who have a registered work disability. Persons that might become relevant for the researcher can be denoted $S_{d_{t}}$, with $S_{d_{t}} \in\{0,1\}$, where $S_{d_{t}} \in S$ and $d_{t} \in\{0,1\}$.

\footnotetext{
${ }^{3}$ The main reason for introducing a time period $t+2$ in the model is simply to take account of the time lag that use to arise before an event, such as being employed or unemployed in period $t+1$, will show up in the data that a researcher is using. For the following discussion only periods $t$ and $t+1$ are essentially needed.
} 
Here $d_{t}$ indicates if a person has a registered disability or not in period $t$. All persons included in $S_{d_{t}}$ have in common that they have an underlying, sometimes undocumented, work disability that is constant over time. Once a work disability has been registered such information stays there over subsequent periods, so that

$S_{d_{t+1}} \in\{0,1\}$, where $S_{d_{t+1}} \in S_{d_{t}}$ and $d_{t+1} \in\{1\}$.

One common aspect for all persons included in sample $S_{d_{t+1}}$ is that they all have a work disability registered in period $t+1$, such that $d_{t+1}=1$. This implies that a person, no matter if belonging to the treatment or control group, can have a registered disability in period $t+1$ without having it in period $t$, while it is not possible to have a registered disability in period $t$, but not in period $t+1$. From this it follows that $d_{t+1}=1$, i.e. being registered with a disability in period $t+1$, is depending on that the individual either has been "awarded" a disability code already in period $t$, i.e. $d_{t}=1 \rightarrow d_{t+1}=1$, or, in case he/she did not already have a code in period $t$, he/she is unemployed in period $t+1$, i.e. $u_{t+1}=1$, with $u_{0}$ indicating if a person is unemployed or not in a given period. A person with undocumented disability in period $t$, who left registered unemployment for starting a job in period $t+1$, will not be assigned a disability in the employment office's registers and therefore that person never shows up in the researcher's data picking persons with registered work disability (extracted in period $t+2)$. In the Appendix, figure A1, a process map is shown that aims to illustrate how the sample used by the researcher is determined.

The fact that a person is unemployed in period $t+1$ to certain extent is the outcome of individual productivity related characteristics, call them $X_{i}$, which for ease of discussion are assumed to be time constant for each individual over period $t$ and $t+1$; one of those characteristics is his/her (un)documented work disability. 
Let $U_{t+1}^{1}$ and $U_{t+1}^{0}$ be the stock of unemployed in period $t+1$ for persons in the treatment (superindex=1) and control group (superindex=0), respectively. From the set-up outlined above it follows that $U_{t+1}^{1}<U_{t+1}^{0}$. This implies that the probability in period $t$ of staying unemployed in period $t+1$ is smaller for persons in the treatment group than in the control group:

i) $\quad P\left(u_{t+1}=1 \mid S_{d_{t}}=1\right)<P\left(u_{t+1}=1 \mid S_{d_{t}}=0\right)$.

According to the made assumptions, the probability of having a work disability registered in period $t+1$ is smaller for those who did not have a code already in period $t$ :

ii) $\quad P\left(d_{t+1}=1 \mid d_{t}=1\right)=1 ; P\left(d_{t+1}=1 \mid d_{t}=0\right)<1$.

In case a person is unemployed in period $t+1$ he/she gets his/her work disability registered with certainty:

iii) $\quad P\left(d_{t+1}=1 \mid d_{t}=1 ; u_{t+1}=1\right)=1 ; P\left(d_{t+1}=1 \mid d_{t}=0 ; u_{t+1}=1\right)=1$.

The researcher departs from the set of persons observed with registered disability in period $t+1$, i.e. the data set $S_{d_{t+1}}$. Those in the treatment group $\left(S_{d_{t+1}}=1\right)$ will determine the reference sample, for which the researcher is trying to find matching "statistical twins" from the sample of persons with registered work disability not taking part in the program $\left(S_{d_{t+1}}=0\right)$. This process, regularly conducted by using a "propensity score" approach, will map each individual in the treatment group to a person in the control group. Matching will be based on observable characteristics that are available in the registers at time $t+2$.

\subsection{Selection based on individual characteristics}

Given that program participants have a higher outflow to work, it follows that to observe a person being unemployed in period $t+1$ among persons participating in the program in 
period $t$, i.e. $S_{d_{t}}=1$, their productivity related characteristics on average will be (weakly) inferior compared to those persons not participating in the program in period $t$ (i.e. $S_{d_{t}}=0$ ) and that are unemployed in period $t+1$. Stated differently, becoming unemployed is less likely to occur for program participants, so that for persons that nevertheless become unemployed these are going to have inferior productivity-related characteristics; the argument for this is that to a larger extent those persons in the lower end of the distribution of participants in $S_{d_{t}}=1$, i.e. those participants that are relatively less productive (e.g. those with lower education and/or less work experience) will show up as unemployed in period $t+1$. Importantly, this kind of downward selection with respect to productivity-related characteristics of persons that become unemployed in period $t+1$ will be more pronounced for those who participated in employment training than what is the case for persons in the control group. From this follows that the sample of persons being unemployed in period $t+1$ will look different with respect to individual characteristics of program participants and persons belonging to the control group, respectively:

$$
U_{t+1}^{1}\left(\bar{X}_{d}^{1}\right) \cong U_{t+1}^{0}\left(\bar{X}_{d}^{0}\right) \Rightarrow \bar{X}_{d}^{1} \preccurlyeq \bar{X}_{d}^{0}
$$

where $\bar{X}_{d}^{1}, \bar{X}_{d}^{0}$ are average productivity related characteristics for persons in the treatment and control group, respectively. In case all relevant variables $\mathrm{x}_{\mathrm{j}}$ in $X_{d}^{1}$ and $X_{d}^{0}$ are observable (and registered) in the data and thus can be controlled for, such stratification with respect to individual characteristics might not bias estimations of treatment effects of participating in employment training. Conversely, in case some variables are not observable or registered (e.g. such as how ambitious a person is, or some more complex forms of functional impairment), there is a risk for ending up with estimations that are biased due to systematic differences across the populations forming the program and control group. 
Some reader might object that the negative selection of persons in the treatment group that are unemployed in period $t+1$, i.e. $\bar{X}_{d \mid u_{t+1}=1}^{1} \preccurlyeq \bar{X}_{d \mid u_{t+1}=1}^{0}$, will be outweighed by a equivalently positive selection of persons in the treatment group that will be employed in period $t+1$, i.e. that $\bar{X}_{d \mid u_{t+1}=0}^{1} \geqslant \bar{X}_{d \mid u_{t+1}=0}^{0}$. The problem, however, is that the sample of persons that in period $t$ were "at risk" of being coded as having a work disability and that are employed in period $t+1$ will not show up in the researcher's data (i.e. the data extracted for the purpose of looking at persons with work disability). On an aggregate level there is thus a negative bias as to productivity related characteristics of treatment group members compared to those persons making up the control group.

\subsection{Outcome dependent selection into treatment and control group}

The preceding discussion has focused on (negative) selection of program participants with respect to productivity related characteristics in the data used by the researcher for the purpose of evaluating program effects for the population of persons with work disabilities. Beside the issue of systematic differences with respect to underlying productivity-related characteristics, i.e. that $\bar{X}_{d}^{1} \neq \bar{X}_{d}^{0}$, there is another, mere arithmetic mechanism that will affect the estimations conducted by the researcher. This is due to the fact that among those persons who do not have a registered disability at time $t$ (among all unemployed persons in period $t$ with an underlying functional impairment, i.e. $S_{d_{t}}$ ) only those will get a code assigned that turn out to be unemployed at time $t+1$. So even if it would be perfectly random which persons remain employed among program participants and comparison group members in time $t+1$, such that $\bar{X}_{d}^{1} \approx \bar{X}_{d}^{0}$, there will be a systematic bias that relates to the mere number of persons observed with work disability in period $t+1$ that found a job or not. Under the assumption outlined above, those persons that once started the program 
in period $t$ who went from being unemployed in period $t$ to become employed in period $t+1$, and who did not have a registered disability already in period $t$, will not show up in the researcher's sample of persons with disability. Thus, estimations that measure the outflow to work do not account for those people in $S_{d_{t}} \in\{0,1\}$, where $d_{t} \in\{0\}$, that actually found work. In contrast, those belonging to $S_{d_{t}} \in\{0,1\}$, where $d_{t} \in\{0\}$, that did not(!) find work will be included in the data used by the researcher. Under the initially made assumption that there is a (general) positive effect of participating in the program out to work, there will be a greater number of positive outcomes, i.e. employed persons among participants, that do not show up in the researcher's data in period $t+1$, compared to what is the case the group of non-participants. This will affect the measured effects with respect to outflow to employment, no matter how many control variables a researcher can possibly put in the (propensity score) matching algorithm to try to equal out differences across persons with respect to each individual's likelihood of treatment assignment and employment prospects. Thus, this kind of outcome dependent selection into the researcher's data will add to the selection bias with respect to productivity related characteristics addressed in the previous section and likely contribute to underestimate the effects of participating in employment training for persons with work disability.

\subsection{Selection to program based on registered work disability}

The discussion so far has been based on the assumption that assignments to program or control group have not been conditioned on having a registered work disability. What would happen if we would drop such assumption, i.e. considering the situation if having a registered work disability would be used as criteria for program assignment? Actually, this would imply that program participants by default would have a registered work disability already in period $t$, while persons forming the control group to some extent would be taken 
from a sample of persons that got their work disability registered in the subsequent period.

More formally this can be described as follows: for participants one would have

$S_{d_{t}} \in\{1\}$, where $d_{t} \in\{1\}$, while the situation for the control group can be described as

$S_{d_{t}} \in\{0\}$, where $d_{t} \in\{0,1\}$. This would systematically affect results to the disadvantage of

the control group as the sample of persons used by the researcher to be matched to

participants to some extent would be taken from a group of persons unemployed at period

$t+1$. Using the notation from section 2.1 above, this can be described as follows. For program participants used in the estimation one would have $P\left(d_{t+1}=1 \mid d_{t}=1\right)=1$, i.e. saying that they have had a registered work disability at period $t$ and are selected into the researchers sample no matter if they are to become unemployed in period $t+1$ or not. For persons that eventually are matched to those participants, however, the situation looks as follows:

$$
P\left(d_{t+1}=1 \mid d_{t}=0\right)<1 ; P\left(d_{t+1}=1 \mid d_{t}=0 ; u_{t+1}=1\right)=1
$$

saying that a certain number of persons in the control group would be chosen among those that received a registered work disability due to the fact that they were unemployed at period $t+1$. Such systematic differences in the selection process, where selection into the comparison group would be partly endogenous, would lead to an upward bias rather than downward bias of measured effects of participating in employment training with respect to outcomes such as being employed or not in period $t+1$.

\section{Empirical Analyses}

In this section we aim to look at how the previous discussion on timing of registration of work disability could affect estimations of participating in ALMP programs based on real world situations. In case it should turn out that differences in estimated effects would be small, one should not be too concerned about "post-registration" of work disability. 
Conversely, if there are significant differences, this kind of endogenous selection should be taken into consideration on a more regular base by researchers active in the field of program evaluation of ALMP programs.

The program evaluated for that purpose is vocational employment training in Sweden over the period 2000 to 2012 . The program aims to give participants the opportunity to learn vocational skills to increase their chances of finding a job. In general the length of the program should not last longer than six months. Estimations are based on propensity score matching methods, with a matching algorithm taking account of a great number of variables, such as age, sex, education level, country of birth, citizenship, state he/she is living, marital status, number of children at home, "inter-local applicants" (that is, if the person applied for work outside his/her domicile), the number of previous periods of registered unemployment and the total length of previous employment (counted in days) based on a five year window counted backwards from the time when starting the program, as well as annual income and received social assistance in the two years preceding program start; in addition persons are exactly matched with respect to the month they were registered unemployed. We also apply exact matching on the time of unemployment before starting the program, in line with the approach proposed in Fredriksson and Johansson (2008). Before running the propensity matching procedure we condition on both participants and (would be) control persons to have a registered work disability. Only program participants are included that have not started an ALMP program since being registered in the current unemployment spell; for the comparison group it is required that they have not entered any program until the time (i.e. the end of the month) they were matched to their statistical twin in the treatment group. Persons included in the control group might enter ALMP programs (the same kind of program or another ALMP-program) at a later stage. This implies that the estimations 
consider the effect of participating in vocational employment training compared to not participating in any ALMP program yet, but possibly in following periods.

In the estimations shown in figure 1 the exact timing for registration of work disability has been taken into account. More specifically this is achieved by removing all persons from the data who received their code after starting to participate in the program. ${ }^{4}$ Overall the measured effects from participating in employment training are positive, which is in line with results presented in other studies; see e.g. Regnér (2014).

Figure 2 shows the outcome when one does not (!) take into account the timing of when the code has been set. The estimates are consistent with those presented in figure 1, except for the fact that the measured effects in figure 2 most of the time are somewhat smaller than those shown in figure 1 . This holds true for both outcomes studied here, i.e. leaving unemployment for "ordinary" employment, as well as outflow to employment that includes both ordinary and subsidized employment. The differences are most pronounced when looking at outcomes that include both ordinary and subsidized employment for persons entering employment training before the year 2006.

\footnotetext{
${ }^{4}$ All persons who have taken part in employment training and had a coding of disability (called "AHKP" in Swedish registers, which also can be found in the "LISA" data provided by Statistics Sweden) have been extracted from data at the Swedish Employment Service. We have information regarding the exact date when the registration of work disability code was done; that information is taken from a register that take account of all entries made by the caseworkers who administer the personal file of an unemployed.
} 
Figure 1

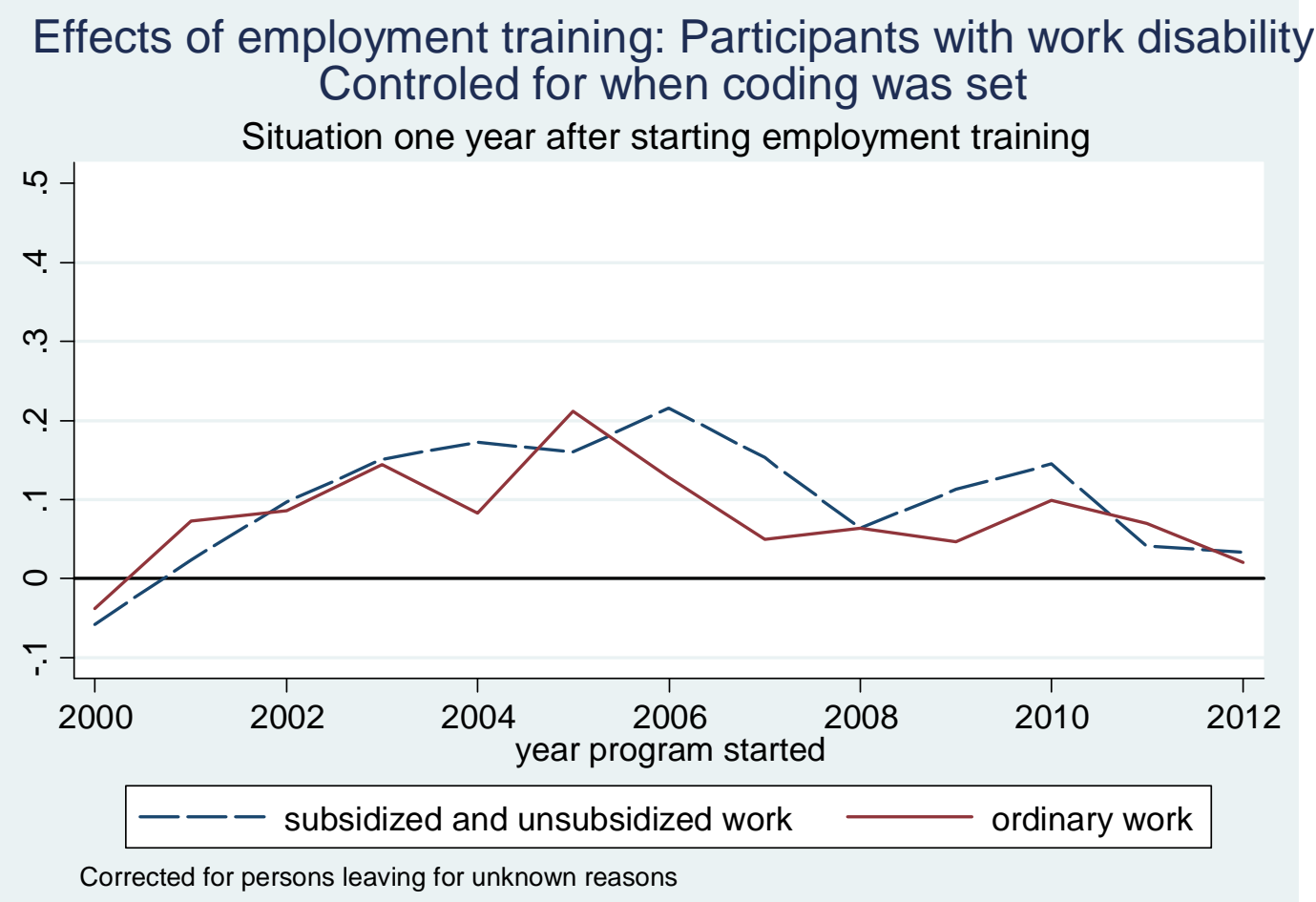

Figure 2

Effects of employment training: Participants with work disability

Not controled for when coding was set

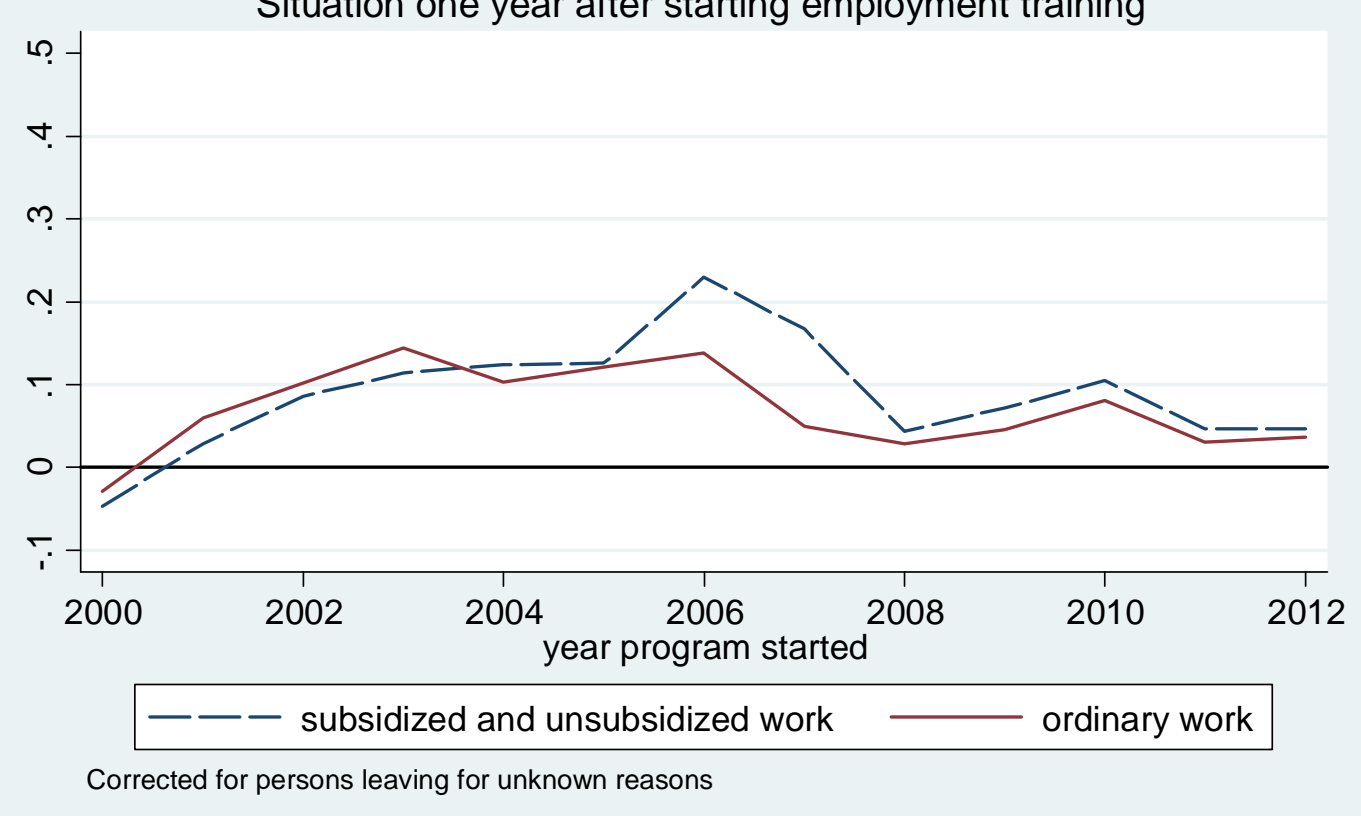


For the year 2004 there is a difference of about six percentage points, i.e. the difference between an effect of about 18 percentage points in figure 1 compared to 12 percentage points in figure 2 in the outcome including ordinary and subsidized employment one year after starting employment training. Before 2006 the differences vary to some extent, but overall there is a rather consistent pattern, suggesting that not controlling for time of registration of work disability leads to smaller estimated effects. ${ }^{5}{ }^{6}$ Such results are in line with the predictions made out from the set-up in the sections 2.2 and 2.3 , predicting smaller effects when not condition on the time when a work disability has been registered.

In total there are 3308 participants in employment training that are removed from the sample used in the estimations shown in figure 1 by conditioning on that registration of a disability should have occurred not later than at start of the program. The number of persons affected by this requirement aggregates to nearly half the sample used for

\footnotetext{
${ }^{5}$ Regnér (2014) mentions that he conducted sensitivity estimations that excluded those persons where the date for registration of disability code was set after program start. Consistent with results shown above, the estimated effects became more positive when restricting the sample to include only those who had a registered disability code before starting employment training.

${ }^{6}$ We have to take into account those persons who have left registered unemployment without notifying the local PES. Based on results by Bring and Carling (2000), regularly one assumes that about $40-50$ percent of those who left for unknown reasons actually did find a job. Those persons who have a work disability, however, most likely have lower transitions to work. According to estimates by Regnér (2014), who looks at registered incomes for persons the month after they left for unknown reasons, differ transition to work between participants and comparison persons, with calculated transitions of 35 (23) and 25 (12) percent of participants and comparison subjects if one requires that the monthly income shall be greater than 0 (5000) SEK. In our estimation we assume that 23 percent left for unknown reasons find work, without differentiating between participants and persons in the comparison group.
} 
estimates shown in figure 2, with 6953 (matched) participants. Notice that such registration requirements of the time a work disability has been registered have to hold true for both treatment and control group. Let's call the time it takes from registering the work disability code to the start of the program for "waiting time (to program start)" ${ }^{7}$ Of those 3308 persons not included in the estimations shown in figure 1 there were 1685 program participants who had a "negative" waiting time, i.e. they received their coding after they began to participate in employment training. The other 1632 participants excluded actually had a "positive" waiting time, but these persons were matched to a person in the control group who had a "negative" waiting time.

For more recent years, especially since 2011, the differences between estimations in figure 1 and figure 2 decline, or even vanish. One explanation for this result is that there has been a general decline in the measured effects of taking part in employment training since 2008, see PES (2014). To some extent this mirrors the fact that the incoming liberal-conservative government that came to power at the end of 2006 adopted a number of regulatory changes that subsequently affected the selection process into ALMP programs. As a consequence, to a larger extent persons less attached to the labour market were assigned to ALMP programs. After 2006 the number of persons with work disability among program participants gradually increased, suggesting that having a registered work disability sometimes might have been used as criterion for assigning persons to employment training, following that change of

\footnotetext{
${ }^{7}$ For the control group the date that is taken into account for estimating his/her waiting time is the last day in the month the respective matched person in the treatment group started the program.
} 
policy. ${ }^{8}$ This has indeed some relevance for our attempts to evaluate labour market programs, among others it reduces applicability of the model presented and discussed in section 2.2 and 2.3 above. Instead such mechanisms as discussed in section 2.4 could have become more relevant. Thus, the way participants were selected to employment training before 2006 has been gradually offset due to more recent policy changes, among others advising case workers at the PES to prioritise persons less connected to the labour market, such as unemployed having a registered work disability, when assigning persons to employment training. One explicit policy change was that the share of persons with functional impairment in employment training should significantly exceed the share of other groups according to ordinance from $2001 .{ }^{9}$

\section{Discussions}

The previous section has shown that there are notable differences when it comes to measuring the effects of employment training for persons with work disability, depending on whether one takes into account the timing of when a functional impairment has been recorded. As argued above, it is recommendable to exclude persons that were assigned a

\footnotetext{
${ }^{8}$ See figure A4 in the Appendix for how the numbers of participants have developed over the course of the studied period.

${ }^{9}$ According to Angelov and Eliason (2014b) were those goals formally incorporated first in 2004. As from 2006/2007 was there focus on "prioritized groups", e.g. persons with cognitive and mental disabilities "that extensively reduced work capacity", p.11; see also PES (2014) for a discussion of recent developments in Swedish labour market policies. As from the year 2011 a new practice was established, forcing those who had passed the maximum number of sick pay days to register with the employment service. This policy change notably increased the number of persons with (registered) work disability in PES registers. This may have contributed to the absent differences in figure 1 and figure 2 for the years 2011 and 2012.
} 
disability code after they started the program. The example used for describing the underlying processes regards a program thought to have a positive impact on participants' chances of becoming employed. To some extent this was done for ease of presentation; obviously, a program could have zero or even negative effect on labour market outcomes. In a setting where program participation would have a negative impact, the bias emerging from not taking into account time of registered work disability could take an opposite direction.

Another way of assessing the importance of taking account of time of disability registration is to look at the (policy) question that one intends to address in an evaluation study. The question addressed by restricting the sample with respect to the time of registration is as follows: "How will the effects of participating in employment training look like for people who have a registered disability?" Not taking into account the timing of registering work disability in PES's records will rather address the question: "How will the effect of participating in employment training look like for people who have registered disability, or who will have a registered disability in the future?" As it is notoriously difficult to predict the future, i.e. if or when a person will receive a work disability registered, the previous position appears to be of greater relevance for scheduling ALMP-measures than the latter. ${ }^{10}$

\footnotetext{
${ }^{10}$ For some reasons one might be interested in studying questions such as the following: "What is the likely impact of participating in a program today for persons who will become registered with a work disability in the future?" To answer that question is, however, rather challenging. This follows from that observed and unobserved characteristics of those who will become classified as having a disability are likely to differ between persons in the treatment and control group, respectively, meaning that one cannot simply compare those (future) disabled to evaluate the value of taking part in a program today. See Zhang et al (2009) for a discussion on the issue of outcomes that are determined by post treatment measurement status.
} 
A third argument in favour of taking into account the time functional impairment has been registered when evaluating ALMP programs is the fact that there are certain supportive measures that only apply for persons who have a documented disability. In particular, individuals with documented work disabilities might have access to certain types of wage subsidies; see Hartman (2011) and Angelov and Eliason (2014a), for an overview of such interventions in Sweden. If one measures the outcomes that include subsidized work, as it is done in the outcome "unsubsidized and subsidized work" shown in figure 1 and 2, persons who at the time they began a labour market program did not have a registered disability clearly had a disadvantage in finding work compared to those individuals who had a registered disability already at the start of the program. Such different initial prospects for people with and without registered disabilities could distort the reliability of found results if not controlled for. ${ }^{11}$

The issue addressed in this study should also be taken into account in situations where the focus is not solely on the group of disabled participants per se, but also in the rather common situation where the researcher is including an indicator for being disabled as control variable in evaluations of ALMP programs. As the indicator that is indicating if a person has a work disability to some extent is determined by the outcome variables, i.e. the fact that the length of time it takes to leave unemployment by itself increases the probability that a work disability is going to be registered, this raises concerns regarding the reliability of

\footnotetext{
${ }^{11}$ According to Angelov and Eliason (2014a) has there been a locking-in effects for those with subsidized employment, leading to reduced outflow to unsubsidized employment.
} 
program evaluations not only for those persons with a work disability, but to some extent this is questioning the reliability of program evaluations more in general. ${ }^{12}$

\section{Conclusions}

As this report has shown, it is important to hold track of the actual timing of registering disability status when studying the impact of ALMP programs for participants with functional impairments. The share of participants in employment training in Sweden that have a registered work disability has been in the range of approximately 10-15 percentage points in recent years. Even if this is not a huge number, it is significant and too large to be ignored. Also, more and more persons with registered disability can be found in the official registers of the Swedish Employment Service (PES), so that the number of persons with some form of disability that will take part in ALMP measures, such as employment training, can be expected to rise in the years ahead.

There are signs that the nature of functional impairment has changed, where work disability to an increasing degree refers to mental disabilities; in the Appendix, figures $A 2$ and $A 3$

\footnotetext{
12 Indeed, it is rather common in evaluations of labour market programs to include an indicator for being disabled in the (propensity score) estimations, see e.g. Regnér (2002), Kluve et al. (2012), Bennmarker et al. (2013), or Lechner and Wiehler (2013). Lechner and Vazquez (2011) discuss the issue of endogenous control variables in their analysis of the effect of disability on labour market outcomes. As they argue, some control variables might be influenced due to a person being disabled, such as the area a person is living. Their advice is to exclude all variables that could have been affected by disability status and that are related to employment outcomes when trying to estimate the marginal impact of having a disability. They also discuss the fact that becoming disabled is not a random event by itself as it can be dependent of potential labour market outcomes.
} 
document this shift. ${ }^{13}$ To some extent such development can be explained by the fact that an increasing number of persons are registered in PES's registers that once migrated as refugees to Sweden. Recent studies have shown that traumatic experiences can constitute a long lasting mental health burden, see Mölsä et al. (2014); especially post-traumatic stress disorders (PTSD) are commonly found among refugee migrants, a result seen in many countries, see Devillé et al. (2012). Symptoms of PTSD regularly unfold several years after the traumatic events took place, see Smida et al. (2011). This suggests an extensive risk that many of current and future refugee migrants will be diagnosed with mental health impairment (long time) after they have been registered in PES's records. ${ }^{14}$

Another factor explaining this shift and strengthening the importance of holding track of when a person receives a work disability registered is the fact that an increasing number of persons, especially young adults, are found to have some kind of mental impairment. The numbers of young persons with some mental disorder has been rising, in Sweden as well as in most other developed countries; see e.g. Nuffield Foundation (2012). Once these persons enter the labour market, many of them will show up in PES's records; while some are registered with a work disability already at the time they are registered as unemployed, for others this will not be the case before some time has passed, for example because a case

\footnotetext{
${ }^{13}$ For a discussion on different classifications of the PES' occupational disability coding system see Angelov and Eliason (2014b).

${ }^{14}$ According to the Swedish PES for the year 2013 on average it took about 260 days to get a work disability registered from being registered as unemployed. For unemployed persons born outside Sweden the average time was 356 days.
} 
worker eventually becomes aware of that there is reason to believe that a person is suffering from some kind of (mental) disorder.

To the best of our knowledge, the kind of "ex post endogenous sample selection" as discussed in this paper has not been addressed, at least not explicitly, in the ALMP evaluation literature before. Conducting the kind of computations as done and proposed in this study requires detailed information on timing of events (i.e. day of start of program and registration of work disability coding, respectively), which might not be easily accessible, at least not on a regular base. Nevertheless, the message from this study is that researchers in the field of ALMP evaluation should become aware of that their estimations regarding the effect of ALMP programs that include a significant number of participants with underlying work disability are at risk of being biased due to "noisy" data. It could be tempting to consider excluding all persons with registered work disability from evaluations of ALMP program estimations in situations where the dates of registration is not known exactly. However, this clearly would put in question extern validity of found results, given that the number of persons with some kind work disability in the labour market can be expected to rise in the near future. 


\section{References}

Angelov, Nikolay and Marcus Eliason (2014a), "The effects of targeted labour market programs for job seekers with occupational disabilities", IFAU Working paper 2014:27, Uppsala

Angelov, Nikolay and Marcus Eliason (2014b), “Factors associated with occupational disability classification", IFAU Working paper 2014:25, Uppsala

PES (2014), "Labour Market Report 2014: SUMMARY", Swedish Public Employment Service. http://www.arbetsformedlingen.se/download/18.362b127c14924e08e8712a3/1415027809 988/Arbetsmarknadsrapport2014_Sammanfattn_Eng1.pdf

Bennmarker, Helge, Oskar Nordström Skans and Ulrika Vikman (2013), "Workfare for the old and long-term unemployed", Labour Economics, Vol. 25, 25-34.

Bring, Johan and Carling, Kenneth (2000), "Attrition and Misclassification of Drop-outs in the Analysis of Unemployment Duration", Journal of Official Statistics, Vol. 16, 321-330.

Devillé WLM, Lindert J, Grujovic G, lodice J, Petrova R: Refugee Health. In Refugees Worldwide, Volume 2. Edited by Elliott D, Segal UA. Santa Barbara, California: Praeger; 2012 Forslund, Anders, Linus Liljeberg and Leah von Trott zu Solz (2013), “Job practice: An evaluation and a comparison with vocational labour market training programmes", IFAU Working Paper 2013:6, Uppsala.

Fredriksson, Peter and Per Johansson (2008), “Dynamic Treatment Assignment: The Consequences for Evaluations Using Observational data", Journal of Business \& Economic Statistics, Vol. 26, 435-445. 
Garsten, Christina and Kerstin Jabobsson (2013), "Sorting people in and out: The plasticity of the categories of employability, work capacity and disability as technologies of government", Ephemera: Theory and Politics in Organization, Vol. 13, 825-850.

Holmqvist, Mikael (2008), "Creating the Disabled Person: A case study of recruitment to 'work for the disabled' program", Scandinavian Journal of Disability Research, Vol. 10, 191-207.

Hartman, Laura (2011), "Swedish policies for the disabled. What do we know about the effects", presented at the conference Labour Activation in a Time of High Unemployment, November 13-15, 2011.

Johansson, Per and Per Skedinger (2005), “Are objective, official measures of disability reliable?", IFAU Working Paper 2005:14, Uppsala.

Johansson, Per and Per Skedinger (2009), “Misreporting in register data on disability status: evidence from the Swedish Public Employment Service”, Empirical Economics, Vol. 37, 411434.

Kluve, Jochen, Hilmar Schneider, Arne Uhlendorff and Zhong Zhao (2012), "Evaluating continuous training programmes by using the generalized propensity score", Journal of the Royal Statistical Society: Series A (Statistics in Society), Vol. 175, 587-617.

Lechner, Michael (2008), “A note on endogenous control variables in causal studies”, Statistics \& Probability Letters, Vol. 78, 190-195.

Lechner, Michael and Rosalia Vazquez-Alvarez (2011), "The effect of disability on labour market outcomes in Germany", Applied Economics, Vol. 43, 389-412. 
Lechner, Michael and Stephan Wiehler (2013), "Does the Order and Timing of Active Labour Market Programmes Matter?", Oxford Bulletin of Economics and Statistics, Vol. 75, 180-212.

Mölsä, Mulki, Raija-Leena Punamäki, Samuli I. Saarni, Marja Tiilikainen, Saija Kuittinen and Marja-Liisa Honkasalo (2014), "Mental and somatic health and pre- and post-migration factors among older Somali refugees in Finland", Transcultural Psychiatry, Vol. 51, 499-525.

Nuffield Foundation (2012), Social trends and mental health: introducing the main findings London: Nuffield Foundation

Regnér, Johan (2014), “Effekter av yrkesinriktad arbetsmarknadsutbildning för deltagare med funktionsnedsättning, 1999-2006", IFAU-Rapport 2014:13, Uppsala.

Regnér, Håkan (2002), “A nonexperimental evaluation of training programs for the unemployed in Sweden", Labour Economics, Vol. 9, 187-206.

Skedinger, Per and Barbro Widerstedt (2007), "Cream skimming in employment programmes for the disabled? Evidence from Sweden", International Journal of Manpower, Vol. 28, 694714.

Smida, Geert E., Gerty J. L. M. Lensvelt-Muldersb, Jeroen W. Knipscheerca, Berthold P. R. Gersonsda and Rolf J. Kleberca (2011), “Late-onset PTSD in unaccompanied refugee minors: exploring the predictive utility of depression and anxiety symptoms", Journal of Clinical Child \& Adolescent Psychology, Vol. 40, 742-755.

Vono de Vilhena, Daniela, Anders Stenberg, Hans-Peter Blossfeld, Elina Kilpi-Jakonen and Yuliya Kosyakova (2012), "The Impact of Formal Adult Education on the Likelihood of Being Employed: a Comparative Overview", Studies of Transition States and Societies, (4.1), 48-68. 
Zhang, Junni L., Donald B. Rubin and Fabrizia Mealli (2009), "Likelihood-Based Analysis of Causal Effects of Job-Training Programs Using Principal Stratification", Journal of the American Statistical Association, Vol. 104, 166-176. 


\section{Appendix}

\section{Figure A1}

Process map describing who will become observed or not observed in the researcher's evaluations of ALMP programs in case one does not condition on that the work disability has been registered before program start.

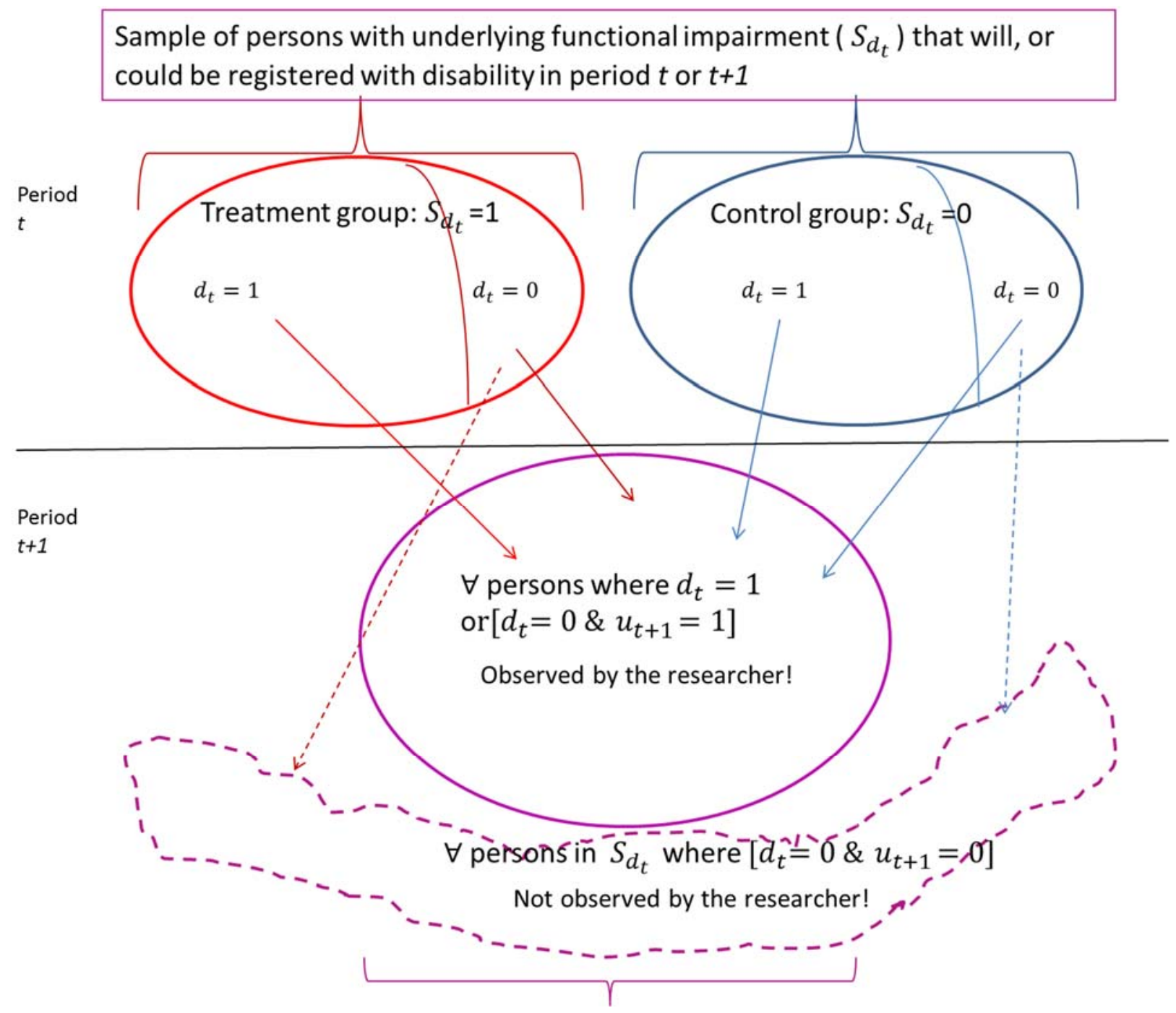

In case there is a positive effect of participating in the program under study, the share of persons employed and not (!) being observed by the researcher that origin from the treatment sample will be larger than those from the control group. 
Figure A2

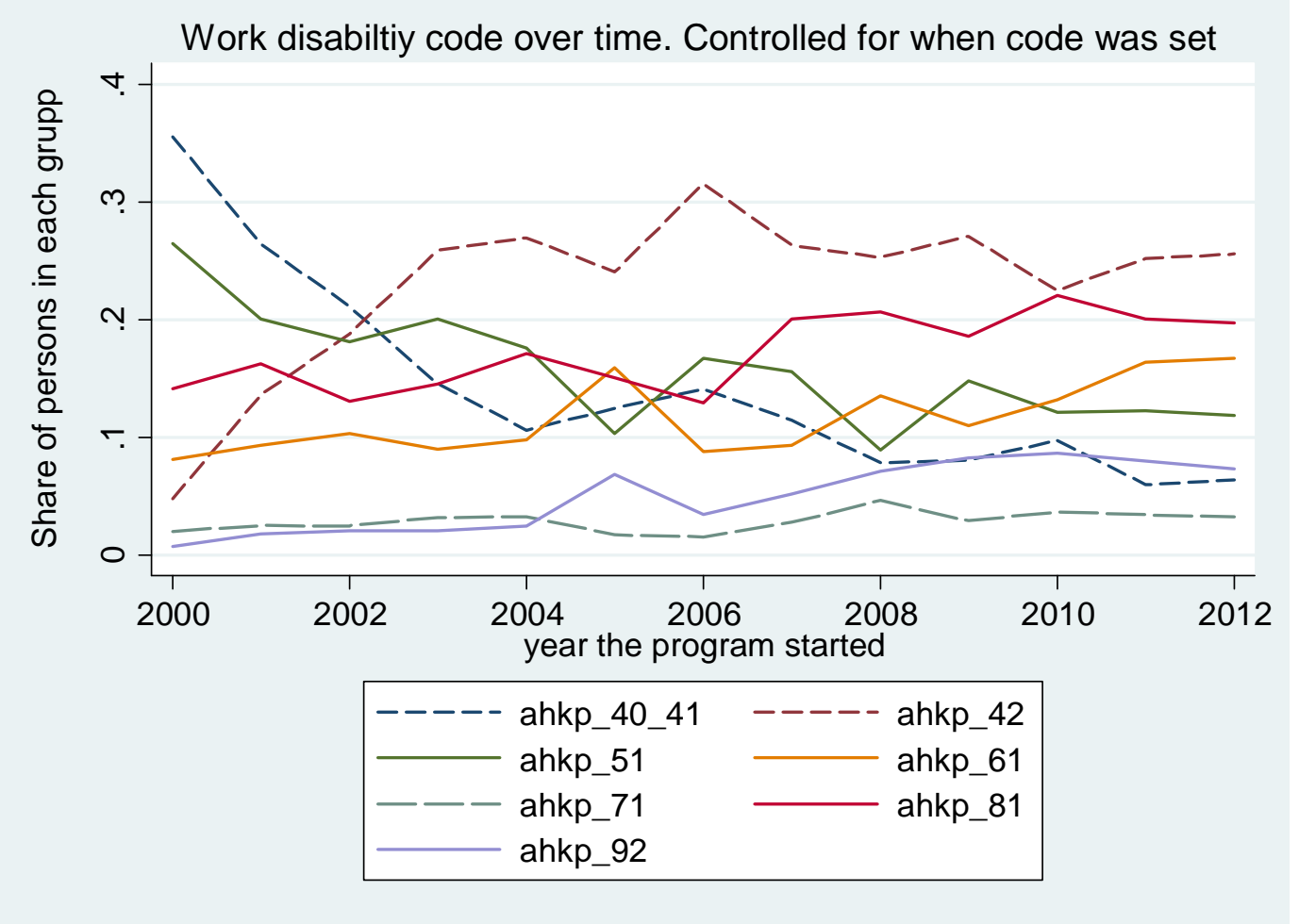

Figure A2 shows that the proportion of people who at the time they entered the program had a registered code associated with mobility issues (codes 40, 41 and 42) were approximately stable when adding these numbers together, but somewhat declining in recent years. Another category declining over time regards the category "somatic disorders", comprising diagnoses such as epilepsy, diabetes, inflammatory bowel disease and psoriasis (code 51). In contrast, the numbers indicating mentally disability (code 61) and the share of persons with specific learning difficulties (code 92) have increased. Also the proportion of individuals who have general learning difficulties (code 71) went up somewhat. The proportion of persons having registered social medical problems (code 81 ) increased to become the second most frequent diagnosis among participants with registered disability code for program participants in the sample underlying results shown in figure 1. 
Figure A3

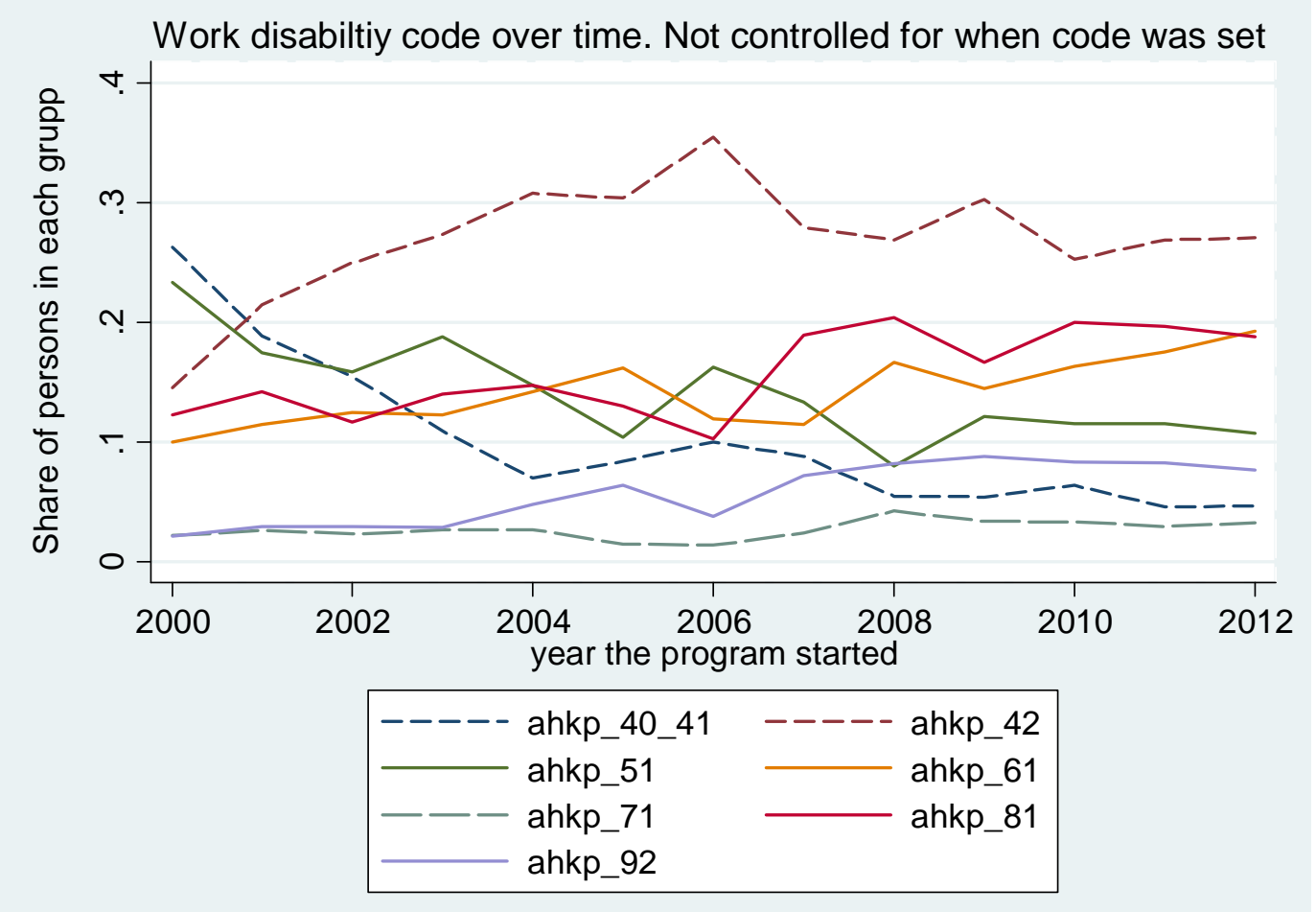

In figure A3 the proportions of different diagnoses for persons with work disability are shown when one does not account for the time of registration of work disability, i.e. the sample used for the results shown in figure 2 . The most prominent difference compared to the shares shown in figure $A 2$ is the somewhat smaller share of persons suffering from social medical problems (code 81) at the end of the observed period. On the other hand, the relative share diagnosed with mental disability (code 61) is somewhat larger on the whole time range covered here. 


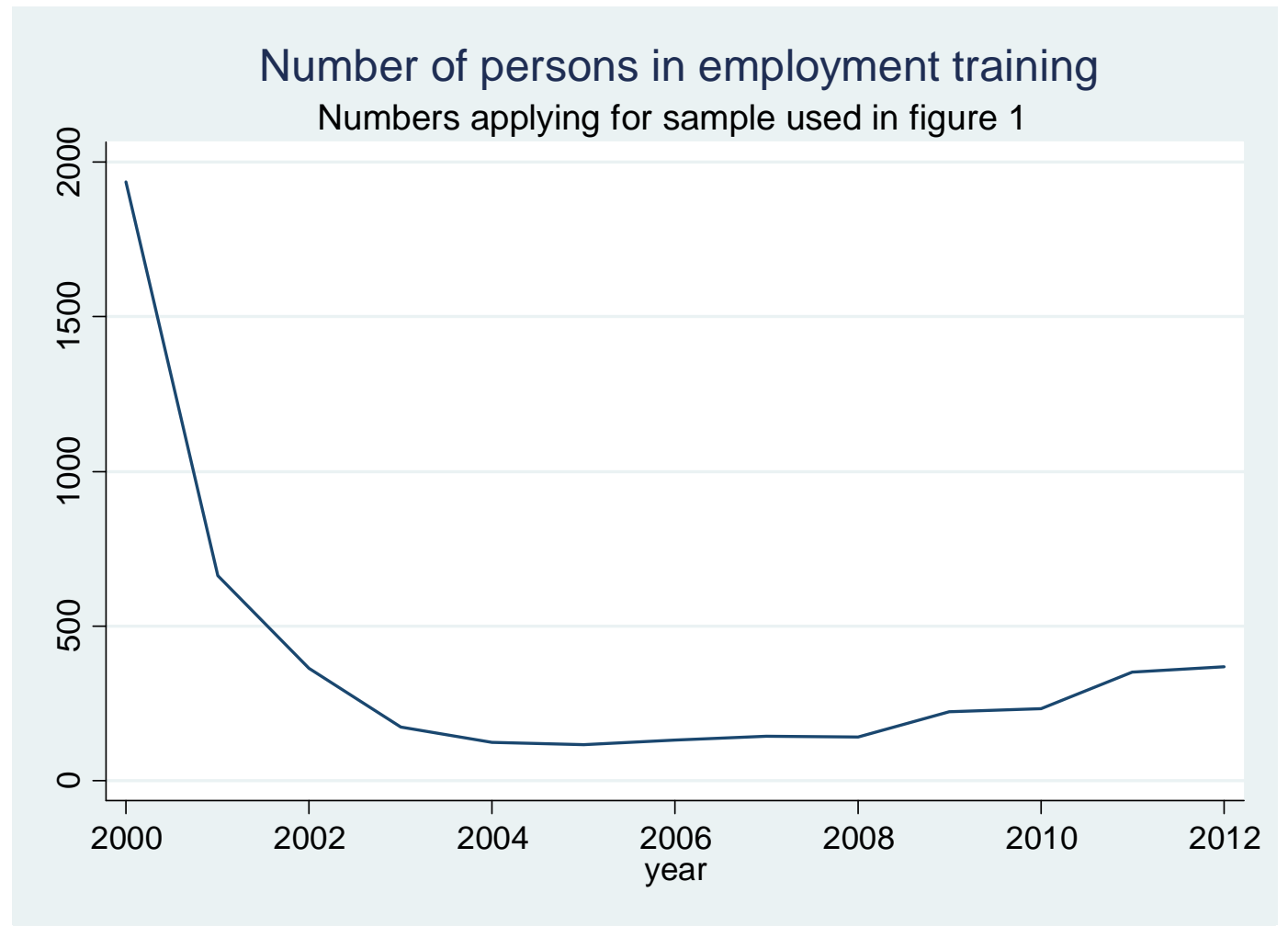

Figure A4 shows the number of persons in employment training in estimation outcomes shown in figure 1 . There is a sharp decline in the numbers from the year 2000 . This mirrors the fact that the number of persons enrolled in employment training were at a very high level at the end of the 1990s, following from the severe financial crisis that hit the Swedish economy some years before. The rise in more recent years, especially for 2011 and 2012, can be explained by policy changes conducted in 2011 forcing persons that previously were on sick leave to register at the PES after they had passed the maximum number of sick days, in combination with a change of policy that implied that only job seekers were assigned to ALMP-programs that were less connected to the labour market. 